University of Nebraska - Lincoln

DigitalCommons@University of Nebraska - Lincoln

\title{
Genetic diversity of resident soil rhizobia isolated from nodules of distinct hairy vetch (Vicia villosa Roth) genotypes
}

\author{
N.V. Mothapo \\ North Carolina State University \\ J.M. Grossman \\ North Carolina State University, julie_grossman@ncsu.edu \\ J. E. Maul \\ USDA-ARS, jude.maul@ars.usda.gov \\ W. Shi \\ North Carolina State University \\ T. Isleib \\ North Carolina State University
}

Follow this and additional works at: https://digitalcommons.unl.edu/usdaarsfacpub

Mothapo, N.V.; Grossman, J.M.; Maul, J. E.; Shi, W.; and Isleib, T., "Genetic diversity of resident soil rhizobia isolated from nodules of distinct hairy vetch (Vicia villosa Roth) genotypes" (2013). Publications from USDA-ARS / UNL Faculty. 1168.

https://digitalcommons.unl.edu/usdaarsfacpub/1168

This Article is brought to you for free and open access by the U.S. Department of Agriculture: Agricultural Research Service, Lincoln, Nebraska at DigitalCommons@University of Nebraska - Lincoln. It has been accepted for inclusion in Publications from USDA-ARS / UNL Faculty by an authorized administrator of DigitalCommons@University of Nebraska - Lincoln. 


\title{
Genetic diversity of resident soil rhizobia isolated from nodules of distinct hairy vetch (Vicia villosa Roth) genotypes
}

\author{
N.V. Mothapo a , J.M. Grossman ${ }^{\mathrm{a}, *}$, J.E. Maul $^{\mathrm{b}}$, W. Shi ${ }^{\mathrm{a}}$, T. Isleib $^{\mathrm{c}}$ \\ a North Carolina State University, Department of Soil Science, 101 Derieux Street, 4242 Williams Hall, Box 7619, Raleigh, NC 27695, USA \\ ${ }^{\mathrm{b}}$ USDA-ARS Sustainable Agriculture Systems Lab, 10300 Baltimore Avenue, Beltsville, MD, USA

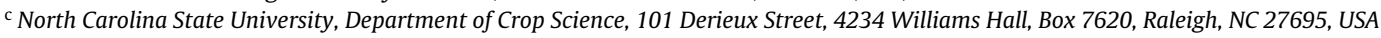

\section{A R T I C L E I N F O}

\section{Article history:}

Received 20 September 2012

Received in revised form

11 December 2012

Accepted 11 December 2012

\section{Key words:}

Genetic diversity

Cropping history

Rhizobium leguminosarum bv. viciae

Hairy vetch

BOX-PCR

\begin{abstract}
A B S T R A C T
Hairy vetch (Vicia villosa Roth, HV) is widely grown as a legume cover crop throughout the U.S.A., with biological nitrogen fixation (BNF) through symbiosis with Rhizobium leguminosarum biovar viciae (Rlv) being one of the most sought after benefits of its cultivation. This study determined if HV cultivation history and plant genotype affect genetic diversity of resident Rlv. Soil samples were collected from within farmers' fields at Graham, Cedar Grove and Ivanhoe sites in North Carolina and pairs of genetically similar hairy vetch genotypes used as trap hosts. A total of 519 Rlv strains were isolated from six paired field soils, three with and three without histories of HV cultivation. A total of 46 strains failed to PCR-amplify the nifH gene; however nodC PCR amplification of these nifH-negative strains resulted in amplification of 22 of the strains. Repetitive element polymerase chain reaction (rep-PCR) with BOX-A1R primer and redundancy analysis showed rhizobial diversity to vary greatly within and between fields, with over 30 BOX banding patterns obtained across the six fields. Cluster analysis of BOX-PCR banding patterns resulted in 36 genetic groups of Rlv at a similarity level of 70\%, with 15 of the isolates from fields with HV history not belonging to any of the clusters. Site was found to be the main driver of isolate diversity overall, explaining $57 \%$, of the total variation among rhizobia occupying HV nodules, followed by history of hairy vetch cultivation. Evidence of a HV host genotype influence on the populations of rhizobia that infect hairy vetch was also observed, with plant genotype explaining $12.7 \%$ of the variation among all isolates. Our results show that second to site, HV cultivation history was the most important driver of rhizobial nodule community structure and increases the genetic diversity of resident Rlv in soils.
\end{abstract}

(c) 2012 Elsevier B.V. All rights reserved.

\section{Introduction}

Hairy vetch (Vicia villosa Roth, HV) is a winter annual legume whose cultivation as a cover crop is common in the US, particularly in organic and low input farming systems. Through symbiosis with Rhizobium leguminosarum biovar viciae (Rlv), HV can contribute significant quantities of nitrogen $(\mathrm{N})$ to farming systems (Power et al., 1991; Sainju et al., 2001), and inoculation of HV with effective Rlv strains to increase $\mathrm{N}$ fixation is a common practice. $R$. leguminosarum bv. viciae are capable of nodulating several legume species belonging to tribe viciae (Laguerre et al., 2003), including pea (Pisum sativum), faba bean (Vicia faba) and common vetch (Vicia sativa). In the absence of legume hosts these soil-borne saprophytic bacteria survive on decomposed organic compounds, and environmental variables and management practices have been shown to affect the Rlv population structure and diversity of Rlv

\footnotetext{
* Corresponding author. Tel.: +1 9195131041.

E-mail address: julie_grossman@ncsu.edu (J.M. Grossman).
}

existing in the field in the absence of a legume host (Bala et al., 2001; Andrade et al., 2002a; Depret et al., 2004; Kaschuk et al., 2006).

Although several studies have reported indigenous or resident soil rhizobia to negatively affect successful symbiotic relationships with legume hosts through competition with inoculant strains (Lima et al., 2009), other studies have shown resident rhizobia to form effective associations, both nodulating and fixing nitrogen with their legume hosts. Resident rhizobia can be defined as those existing in a given soil, including native rhizobia and those previously introduced and naturalized over time. Ballard and Charman (2000) reported symbiotic efficiency, in which $\mathrm{N}$ is fixed and subsequently translocated to the host for improved growth and production, between resident clover rhizobia ( $R$. leguminosarum biovar trifolii) and balansa clover (Trifolium michelianum Savi) to be as high as $128 \%$ of that of the recommended inoculant strain. Other studies have shown reduced symbiotic efficiency between resident rhizobia and pasture medics, with $\mathrm{N}$-fixed ranging between -6 and $72 \%$ of that resulting from the inoculant strain (Ballard and Charman, 2000). 
Understanding how resident rhizobial populations are affected by management, environmental changes and host genotype is critical for improved $\mathrm{N}$ fixation in managed agroecosystems where legumes are used for $\mathrm{N}$ contribution. Soil $\mathrm{pH}$ has been shown to greatly affect rhizobial survival and diversity in soils (Frey and Blum, 1994; Graham et al., 1994; Bala et al., 2001; Andrade et al., 2002a), and fields with low pH often have reduced nodulation (Chemining'wa and Vessey, 2006). Decreased diversity of $R$. leguminosarum biovar phaseoli has been reported in acid soils compared to limed soils (Andrade et al., 2002b; Lapinskas, 2007). Soil management practices have also been shown to affect rhizobial populations, including reports of reduced diversity in long-term monocultures as compared to crop rotation with legume host plants (Depret et al., 2004; Grossman et al., 2011), and high diversity of bean rhizobia in no-till fields compared to conventional till fields (Kaschuk et al., 2006). Past cultivation of a legume host in a given field has been shown to be particularly important in impacting resident rhizobia population size in beans (Andrade et al., 2002a), peas (Chemining'wa and Vessey, 2006), and vetch (Mothapo, 2011).

Hairy vetch cultivars adapted to specific environmental conditions have been developed in order to utilize them in particular agroecological management systems. Examples include the coldtolerant Madison variety from Nebraska, and recent early-maturing USDA-ARS varieties Purple Bounty and Purple Prosperity, which reach peak biomass one to two weeks before standard varieties and allow for early/timely planting of cash crops (Maul et al., 2011). Previous reports assessing diversity among strains of Rlv in agricultural systems demonstrated higher diversity in no-till compared to conventional tillage systems (Ferreira et al., 2000; Andrade et al., 2003; Kaschuk et al., 2006) and higher diversity in arable lands compared to grassland (Palmer and Young, 2000). However, little attention has been given to diversity of rhizobia associating with distinct HV genotypes. Numerous studies have shown the presence of legume host to affect population size and structure of compatible rhizobia in agroecosystems, with nod type being a strong determinant of host preference (Hynes and Oconnell, 1990; Laguerre et al., 2003; Mutch et al., 2003; Mutch and Young, 2004; Laguerre et al., 2007; Depret and Laguerre, 2008). In some species, subtle differences in host genotype at the sub-species level have been shown to select for different populations of rhizobia in a soil (Depret and Laguerre, 2008).

Many certified organic growers in the United States utilize hairy vetch on an annual basis in their fields, however we do not yet understand how past planting of this species might impact the population structure and diversity of resident Rlv populations able to nodulate future plantings of this legume. In this study we evaluated genetic diversity of Rlv isolated from root nodules of ten distinct HV genotypes inoculated with soil dilutions from fields with and without HV cultivation history. Our specific objectives were to: (i) determine the effect of HV cultivation history on the genetic diversity of resident Rlv and (ii) determine genetic relationships among rhizobia occupying nodules in pairs of genetically similar vetch varieties.

\section{Materials and methods}

\subsection{Field sites and soil sampling}

The field study was conducted in 2010 in an agricultural area of the state of North Carolina with numerous certified organic farms, located in the Southeastern region of the U.S.A. Soil samples were collected from three farms with histories of hairy vetch cultivation, including at least five seasons of HV since 1990, located in the cities of Graham, Cedar Grove and Ivanhoe (Table 1). On each farm a paired field which had never been planted to hairy vetch and never observed to have had wild hairy vetch varieties (Personal communication with farmers) was also sampled. Inoculation history on fields having past hairy vetch cultivation differed among farms, with Cedar Grove fields being previously inoculated with each past hairy vetch planting, Graham having no history of inoculation, and Ivanhoe not being inoculated since 2004 .

All fields with vetch history were planted to hairy vetch at the time of sampling, some in mixtures with grass species. Forty soil cores to a depth of $15 \mathrm{~cm}$ and diameter of $2.5 \mathrm{~cm}$ were randomly collected at each field, thoroughly mixed into a representative sample and then stored at $4{ }^{\circ} \mathrm{C}$ in the laboratory. All sampling materials were sterilized with $75 \%$ ethanol prior to sampling and during sampling and handling, with precautions taken to avoid crosscontamination of soils from different fields and sites. From each representative sample, a subsample was taken, dried at $45^{\circ} \mathrm{C}$ and sent to North Carolina Department of Agriculture and Consumer Services, Agronomic Division for chemical analysis.

\subsection{Rhizobia isolation}

Five groups of hairy vetch genotypes were used to trap soil rhizobia over a period of six weeks in a growth chamber. Each hairy vetch group comprised two genotypes closely related in genetic and biochemical characteristics (Table 3) (Maul et al., 2011). Seven of the ten total genotypes were previously collected from Afghanistan, Greece, Iran, and Turkey, while three were varieties recently developed for use as cover crops in U.S. based systems, including USDA releases Purple Bounty and Purple Prosperity early flowering varieties, (USA-MD 1 and USA-MD 2, respectively), and the Madison variety from Nebraska, USA-NE. Seeds for Afghanistan, Greece, Iran and Turkey genotypes were obtained from National Plant Germplasm System (Washington State University, Pullman, WA), and seeds for US varieties were obtained from USDA-ARS Sustainable Agriculture Systems Lab (Beltsville, MD).

Hairy vetch seeds were surface sterilized with $3 \%$ sodium hypochlorite, rinsed five times in sterile deionized water, placed on sterilized germination paper in Petri dishes and left to germinate at room temperature for six days. Seeds showing low initial germination rates were scarified by soaking in $80 \% \mathrm{H}_{2} \mathrm{SO}_{4}$ for $30 \mathrm{~min}$, then rinsing 5 times with deionized water. Two hairy vetch seedlings were planted and later thinned to one seedling per unit. Each seedling was inoculated with $500 \mu \mathrm{l}$ of a $5^{-1}$ soil dilution prepared by mixing $20 \mathrm{~g}$ of soil with $80 \mathrm{ml}$ of $0.85 \%$ (w/v) $\mathrm{NaCl}$ solution (Bala et al., 2001). The 60 combinations were evaluated in the growth chamber in a randomized complete block design with four replications. Due to growth chamber space constraints, replications one and two were established first in May/June 2010 (run 1) and replications three and four second in September/October 2010 (run 2). The growth chamber was set at $9 \mathrm{~h}$ days with $22^{\circ} \mathrm{C}$ day temperature, and $18^{\circ} \mathrm{C}$ night temperature. Sterile $\mathrm{N}$-free nutrient solution was supplied when needed.

Plant roots were harvested after six weeks of growth. Three nodules were randomly selected from each root system, surface sterilized with $3 \%$ sodium hypochlorite and rinsed 5 times in sterile deionized water. The surface sterilized nodules were crushed onto yeast mannitol agar media plates (YMA, Vincent, 1970) containing $0.1 \%$ Congo red and incubated at $28^{\circ} \mathrm{C}$ for 3 days. Rhizobial cultures were repeatedly streaked on YMA to ensure purity and obtain single colonies, and each colony was assumed to represent a single strain (Vessey and Chemining'wa, 2006). A single typical colony was then transferred into tryptone yeast (TY, Vincent, 1970) and shaken for five days at $180 \mathrm{rpm}$. Resulting cultures were centrifuged, supernatant discarded, and isolates placed in $300 \mu$ l sterile water and stored at $-20^{\circ} \mathrm{C}$. Live cultures were maintained on YMA slants at $4{ }^{\circ} \mathrm{C}$. 
Table 1

Characteristics of fields from which soils were collected for inoculation of the ten distinct HV genotypes, modified from Mothapo (2011).

\begin{tabular}{|c|c|c|c|c|c|c|c|}
\hline Site & Soil type & Field history & Status during sampling & $\begin{array}{l}\text { Last inoculation with } \\
\text { Rlv }\end{array}$ & Legume history & Soil $\mathrm{pH}$ & Soil $\mathrm{P}\left(\mathrm{mg} \mathrm{dm}^{-3}\right)$ \\
\hline \multirow[t]{2}{*}{ Graham } & $\begin{array}{l}\text { Appling Sandy Loam } \\
\text { (Fine, kaolinitic, } \\
\text { thermic Typic } \\
\text { Kanhapludults) }\end{array}$ & $\mathrm{HV}+$ & $\begin{array}{l}\text { Hairy vetch, pea and } \\
\text { rye }\end{array}$ & Never been inoculated & $\begin{array}{l}\text { Crimson clover, } \\
\text { cowpea and pea }\end{array}$ & 6.6 & 67.0 \\
\hline & & $\mathrm{HV}-$ & Asparagus grass & - & - & 6.1 & 103.3 \\
\hline \multirow[t]{2}{*}{ Cedar Grove } & $\begin{array}{l}\text { Appling Sandy Loam } \\
\text { (Fine, kaolinitic, } \\
\text { thermic Typic } \\
\text { Kanhapludults) }\end{array}$ & $\mathrm{HV}+$ & Hairy vetch and rye & $\begin{array}{l}\text { Every season hairy } \\
\text { vetch was planted }\end{array}$ & Crimson clover & 6.6 & 328.2 \\
\hline & & $\mathrm{HV}-$ & Grass & - & - & 5.7 & 77.7 \\
\hline \multirow[t]{2}{*}{ Ivanhoe } & $\begin{array}{l}\text { Chipley Sand (Thermic, } \\
\text { coated Aquic } \\
\text { Quartzipsamments) }\end{array}$ & $\mathrm{HV}+$ & Hairy vetch & Not since 2004 & Crimson clover & 5.7 & 497.3 \\
\hline & & $\mathrm{HV}-$ & Weeds & - & - & 5.4 & 658.0 \\
\hline
\end{tabular}

-, Field does not have history of legume cropping or growth, therefore, no inoculation.

\subsection{Genetic characterization}

\subsubsection{Confirmation of isolates: nifH-PCR}

A total of 519 rhizobia were isolated from the hairy vetch genotypes across all treatment replications. Isolates were assumed to be $R$. leguminosarum biovar viciae (Rlv) due to the high specificity between hairy vetch and Rlv. To further support the inclusion of only Rlv in the study, nifH PCR was performed. Amplification of nifH was performed using primers nifH-Forward and nifH-Reverse (Table 2) from New England Biolabs (Ipswich, MA). The PCR reaction contained $1 \mu \mathrm{l}$ DNA template, $3.3 \mu \mathrm{l}$ Taq polymerase, $0.2 \mu \mathrm{l}$ nifH-Forward and $0.2 \mu \mathrm{l}$ nifH-Reverse, made up to final volume of $10 \mu \mathrm{l}$ with sterile water. Amplification was carried out in a Mastercycler ${ }^{\text {ep }}$ thermocycler (Eppendorf, Germany), using the following PCR cycles: initial denaturing at $94^{\circ} \mathrm{C}$ for $5 \mathrm{~min}, 30$ cycles of, denaturing $94^{\circ} \mathrm{C}$ for $1 \mathrm{~min}$, annealing at $60^{\circ} \mathrm{C}$ for $1 \mathrm{~min}$ extension at $72{ }^{\circ} \mathrm{C}$ for $1 \mathrm{~min}$, and final extension at $72{ }^{\circ} \mathrm{C}$ for $5 \mathrm{~min}$. nifH-PCR products were examined via electrophoresis using $1 \%$ agarose gel containing $5 \%$ ethidium bromide (EtBr), run at $100 \mathrm{~V}$ for $40 \mathrm{~min}$. Gels were viewed under UV radiation.

\subsubsection{NodC-PCR amplification}

To eliminate exclusion of Rlv due to possible bias of nifH-PCR, nodC-PCR amplification was performed on a total of 117 isolates, using primers nodC-Forward and nodC-Reverse (Table 2; New England Biolabs), 71 of which were amplified by nifH and 46 were not. The primers were chosen based on their selection by Sarita et al. (2005) as being universally present in many nodulating legume host plants, including Vicia species. The PCR reaction contained $1 \mu \mathrm{l}$ DNA template, $3.9 \mu \mathrm{l}$ Taq polymerase, $0.2 \mu \mathrm{l}$ nodC-Forward and $0.2 \mu \mathrm{l}$ nodC-Reverse, made up to final volume of $11 \mu \mathrm{l}$ with sterile milliQ water. Amplification was carried out in a Mastercyclerep thermocycler, using the following PCR cycles: initial denaturing at $94^{\circ} \mathrm{C}$ for $3 \mathrm{~min}, 30$ cycles of, denaturing at $94^{\circ} \mathrm{C}$ for $1 \mathrm{~min}$, annealing at $55^{\circ} \mathrm{C}$ for $1 \mathrm{~min}$ extension at $72^{\circ} \mathrm{C}$ for $1 \mathrm{~min}$, and final extension at $72{ }^{\circ} \mathrm{C}$ for $7 \mathrm{~min}$. nodC-PCR products were examined via electrophoresis using $1.5 \%$ agarose gel containing $5 \%$ ethidium bromide
(EtBr), run at $100 \mathrm{~V}$ for $40 \mathrm{~min}$. Gels were viewed under UV radiation.

\subsubsection{PCR amplification with BOX A1R primer}

Isolates confirmed to contain either nifH or nodC genes were amplified by repetitive element polymerase chain reaction (repPCR) using BOX-A1R primer to assess genetic diversity. The PCR reaction contained $1 \mu \mathrm{l}$ template, $8.75 \mu \mathrm{l}$ Taq polymerase, $0.5 \mu \mathrm{l}$ BOX-A1R primer, made up to final volume of $25 \mu \mathrm{l}$ using water. The following thermocycler settings were used: initial denaturing at $94^{\circ} \mathrm{C}$ for $5 \mathrm{~min}, 30$ cycles of, denaturing at $94^{\circ} \mathrm{C}$ for $1 \mathrm{~min}$, annealing at $60^{\circ} \mathrm{C}$ for $1 \mathrm{~min}$ extension at $72^{\circ} \mathrm{C}$ for $1 \mathrm{~min}$, and final extension at $72{ }^{\circ} \mathrm{C}$ for $5 \mathrm{~min}$. Products obtained using BOX-PCR were analyzed using horizontal gel electrophoresis in a 3\% agarose gel containing 5\% EtBr. A 10,000 bp molecular marker (Quick Load DNA Ladder III, Apex ${ }^{\mathrm{TM}}$ Bioresearch Products) was loaded alongside BOX-PCR products to estimate the DNA fragment size. Gel was run at $300 \mathrm{~V}$ for $5 \mathrm{~min}$ followed by $18 \mathrm{~h}$ at $80 \mathrm{~V}$ and visualization under UV radiation.

\subsubsection{Cluster analysis}

Cluster analyses performed on the BOX-PCR patterns using the GelCompar II program version 6.1 (Applied Mathematics, Belgium) to construct a dendrogram of similarity for all isolates. One analysis across all sites was performed, followed by three separate analyses, one for each site. The unweighted pair-group method with arithmetic mean (UPGMA) algorithm and the Jaccard coefficient were used. Grouping of isolates into clusters was based on $70 \%$ level of similarity (Grange and Hungria, 2004; Kaschuk et al., 2006; Giongo et al., 2007; de Fatima et al., 2007).

\subsubsection{Ordination and redundancy analysis}

To explicitly test if rhizobial occupancy of vetch nodules was driven by vetch genotype, each vetch genotype was coded as an "environment" factor and then analyzed by redundancy analysis (RDA). The multivariate statistical program Canoco (ver. 4.5 Micropowercomputing Inc., Ithaca, NY) was used to perform the RDA ordination on the rhizobial isolate fingerprint dataset

Table 2

Oligonucleotides used as PCR primers for amplification of the nifH, nodC regions, and sequences located between the BOX regions.

\begin{tabular}{|c|c|c|c|}
\hline Primer & $5^{\prime}-3^{\prime}$ nucleotide sequence & Target gene & References \\
\hline nifH-Forward & GCTGCCTATGCAGACGATG & nifH & Kaschuk et al. (2006) \\
\hline nifH-Reverse & TTACTGGCTTTCATTTGGC & nifH & Kaschuk et al. (2006) \\
\hline nodC-Forward & GCTGCCTATGCAGACGATG & nodC & Sarita et al. (2005) \\
\hline nodC-Reverse & GGTTACTGGCTTTCATTTGGC & $\operatorname{nodC}$ & Sarita et al. (2005) \\
\hline BOX-A1R & CTACGGCAAGGCGACGCTGACG & DNA located between BOX sequences & Kaschuk et al. (2006) \\
\hline
\end{tabular}


Table 3

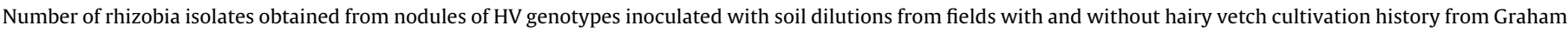
Cedar Grove and Ivanhoe.

\begin{tabular}{|c|c|c|c|c|c|c|c|c|}
\hline \multirow[t]{2}{*}{ Hairy vetch genotype } & \multirow[t]{2}{*}{ Hairy vetch Group } & \multicolumn{2}{|c|}{ Graham } & \multicolumn{2}{|c|}{ Cedar Grove } & \multicolumn{2}{|c|}{ Ivanhoe } & \multirow[t]{2}{*}{ Total } \\
\hline & & $\mathrm{HV}+$ & HV- & $\mathrm{HV}+$ & $\mathrm{HV}_{-}$ & $\mathrm{HV}+$ & $\mathrm{HV}-$ & \\
\hline Turkey 1 & 1 & 6 & 3 & 6 & 5 & 3 & 3 & 26 \\
\hline Turkey 2 & 1 & 5 & 9 & 9 & 6 & 6 & 6 & 41 \\
\hline Iran 1 & 2 & 5 & 3 & 6 & 6 & 3 & 0 & 23 \\
\hline USA-NE & 2 & 11 & 12 & 12 & 12 & 11 & 9 & 67 \\
\hline Afghanistan 1 & 3 & 5 & 9 & 8 & 9 & 9 & 7 & 47 \\
\hline Iran 2 & 3 & 7 & 12 & 10 & 12 & 11 & 12 & 64 \\
\hline Afghanistan 2 & 4 & 11 & 12 & 8 & 12 & 9 & 7 & 59 \\
\hline Greece & 4 & 6 & 5 & 3 & 6 & 3 & 3 & 26 \\
\hline USA-MD 1 & 5 & 10 & 10 & 12 & 12 & 12 & 6 & 62 \\
\hline USA-MD 2 & 5 & 10 & 10 & 9 & 10 & 12 & 7 & 58 \\
\hline Total & & 76 & 85 & 83 & 90 & 79 & 60 & 473 \\
\hline
\end{tabular}

extracted from GelCompar II (coded as "species" in Canoco). The RDA is a linear constrained ordination of the rhizobial fingerprint pattern as determined by the BOX-A1R fingerprint pattern and the resulting biplot clusters isolates with similar patterns close together, whereas dissimilar patterns will be distant from each other within the space of the bi-plot. In a preliminary RDA the "species" dataset was run individually and combined for each site, HV history, growth chamber run (1\&2) and vetch genotype. From this initial run it was determined that site and all soil parameters were highly correlated and in all subsequent runs the soil parameters were dropped from analysis under the assumption that farm location is representative of an integration of all soil parameters at any one site. Farm location (site) and HV history were determined to be the dominant drivers of rhizobial diversity among the isolates. In the final RDA rhizobial fingerprint data were coded as "species", hairy vetch genotype was coded as "environment", whereas site, run and HV history were coded as "environmental co-variates". This approach allowed clustering vetch genotype as an independent variable and clustering and correlation of vectors among genetically similar pairs. Correlations were calculated as a Pearson's correlation where $\operatorname{deg}$ vector $A$ is the measured degrees from zero of the vector of genotype $A$ in the comparison and $\operatorname{deg}$ vector $B$ is the measured degrees from zero of the vector of genotype $B$ in the comparison.

Pearson correlation coefficient

$$
=\text { cosine }\left(p i \times \frac{(\operatorname{deg} \text { vector } A-\operatorname{deg} \text { vector } B)}{180 \operatorname{deg}}\right) .
$$

\section{Results}

\subsection{NifH-PCR and NodC-PCR}

A total of 519 isolates were obtained from root nodules of 10 hairy vetch genotypes inoculated with soil dilutions from six fields. The nifH gene of $473 \mathrm{Rlv}$ isolates could be PCR amplified (Table 3), and despite characteristics corresponding to rhizobial phenotypes, 46 of the isolates failed to amplify, and are henceforth referred to as nifH-negative strains (Table 4). Nearly $60 \%$ of the nifH-negative strains were from Ivanhoe, and across all sites, $50 \%$ were from fields with HV history (Table 4). Interestingly, 22 of the nifH-negative strains were able to be positively amplified using PCR for the nodC gene, supporting characterization as rhizobia. The fewest nifHpositive isolates were obtained from the Iran 1 genotype, followed by Greece and Turkey 1 genotypes, whereas the most isolates were obtained from the USA-NE genotype. Across groups, most nifHpositive isolates were obtained in Group 5 genotypes originating from USA.

\subsection{Cluster analysis of BOX-PCR patterns}

Site was found to be the main driver of isolate diversity overall, however within sites, history of vetch cultivation was shown to be the strongest determinant of grouping patterns. In accordance with the redundancy analysis, site explained the majority, $57 \%$, of the

Table 4

Isolates that failed to PCR-amplify the nifH region, i.e. nifH-negative isolates.

\begin{tabular}{|c|c|c|c|}
\hline Location & Field history & Genotype group & Genotype \\
\hline Graham & $+\mathrm{HV}$ & 2 & USA-NE \\
\hline Graham & $+\mathrm{HV}$ & 3 & Afghanistan 1 \\
\hline Graham & $+\mathrm{HV}$ & 5 & USA-MD 1 \\
\hline Graham & $+\mathrm{HV}$ & 5 & USA-MD 1 \\
\hline Graham & $-\mathrm{HV}$ & 5 & USA-MD 1 \\
\hline Graham & $-\mathrm{HV}$ & 5 & USA-MD 1 \\
\hline Graham & $-\mathrm{HV}$ & 5 & USA-MD 2 \\
\hline Graham & $-\mathrm{HV}$ & 5 & USA-MD 2 \\
\hline Cedar Grove & $+\mathrm{HV}$ & 2 & USA-NE \\
\hline Cedar Grove & $+\mathrm{HV}$ & 3 & Afghanistan 1 \\
\hline Cedar Grove & $+\mathrm{HV}$ & 3 & Iran 2 \\
\hline Cedar Grove & $+\mathrm{HV}$ & 4 & Afghanistan 2 \\
\hline Cedar Grove & $+\mathrm{HV}$ & 5 & USA-MD 2 \\
\hline Cedar Grove & $+\mathrm{HV}$ & 5 & USA-MD 2 \\
\hline Cedar Grove & $+\mathrm{HV}$ & 3 & Iran 2 \\
\hline Cedar Grove & $+\mathrm{HV}$ & 4 & Afghanistan 2 \\
\hline Cedar Grove & $+\mathrm{HV}$ & 4 & Greece \\
\hline Cedar Grove & $-\mathrm{HV}$ & 1 & Turkey 1 \\
\hline Cedar Grove & $-\mathrm{HV}$ & 2 & USA-NE \\
\hline Ivanhoe & $+\mathrm{HV}$ & 1 & Turkey 1 \\
\hline Ivanhoe & $+\mathrm{HV}$ & 1 & Turkey 2 \\
\hline Ivanhoe & $+\mathrm{HV}$ & 1 & Turkey 2 \\
\hline Ivanhoe & $+\mathrm{HV}$ & 1 & Turkey 2 \\
\hline Ivanhoe & $+\mathrm{HV}$ & 2 & Iran 1 \\
\hline Ivanhoe & $-\mathrm{HV}$ & 1 & Turkey 1 \\
\hline Ivanhoe & $-\mathrm{HV}$ & 2 & USA-NE \\
\hline Ivanhoe & $-\mathrm{HV}$ & 3 & Iran 2 \\
\hline Ivanhoe & $-\mathrm{HV}$ & 4 & Afghanistan 2 \\
\hline Ivanhoe & $-\mathrm{HV}$ & 4 & Afghanistan 2 \\
\hline Ivanhoe & $-\mathrm{HV}$ & 5 & USA-MD 2 \\
\hline Ivanhoe & $-\mathrm{HV}$ & 5 & USA-MD 2 \\
\hline Ivanhoe & $+\mathrm{HV}$ & 1 & Turkey 1 \\
\hline Ivanhoe & $-\mathrm{HV}$ & 2 & USA-NE \\
\hline Ivanhoe & $-\mathrm{HV}$ & 3 & Afghanistan 1 \\
\hline Ivanhoe & $-\mathrm{HV}$ & 3 & Iran 2 \\
\hline Ivanhoe & $+\mathrm{HV}$ & 3 & Afghanistan 1 \\
\hline Ivanhoe & $+\mathrm{HV}$ & 4 & Afghanistan 2 \\
\hline Ivanhoe & $+\mathrm{HV}$ & 4 & Afghanistan 2 \\
\hline Ivanhoe & $+\mathrm{HV}$ & 4 & Afghanistan 2 \\
\hline Ivanhoe & $-\mathrm{HV}$ & 3 & Afghanistan 1 \\
\hline Ivanhoe & $-\mathrm{HV}$ & 4 & Afghanistan 2 \\
\hline Ivanhoe & $-\mathrm{HV}$ & 4 & Afghanistan 2 \\
\hline Ivanhoe & $-\mathrm{HV}$ & 4 & Afghanistan 2 \\
\hline Ivanhoe & $-\mathrm{HV}$ & 5 & USA-MD 1 \\
\hline Ivanhoe & $-\mathrm{HV}$ & 5 & USA-MD 1 \\
\hline Ivanhoe & $-\mathrm{HV}$ & 5 & USA-MD 1 \\
\hline
\end{tabular}




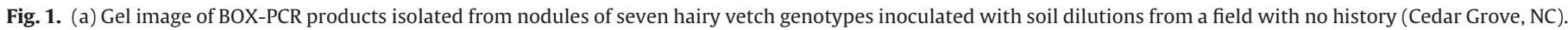

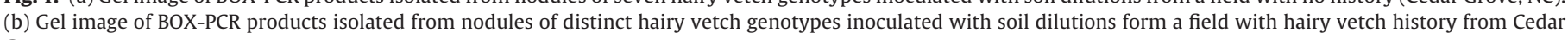
Grove.

total variation among rhizobia occupying HV nodules. Over all three sites, the number of BOX-PCR bands obtained per strain ranged from 3 (isolated from Iran 2 inoculated with soil from Graham field with HV history) to over 25 (originating from Cedar Grove soil) (Fig. 1a and b). Great diversity was observed when all sites were pooled, with a total of 36 clusters identified that contained isolates with greater than $70 \%$ similarity to each other. Fifteen isolates from fields with HV history, and two from fields without HV history were found to have distinct banding patterns differing from a majority of the collected strains, and did not belong to any one cluster, with their most closely related cluster similarity levels ranging from only 28.8 to $55.9 \%$. Significant diversity was observed across the sites, with almost $30 \%$ of the clusters (11) being small and containing only a few strains that were at least $80 \%$ similar to each other. The largest cluster comprised 96 of the total strains, with $90 \%$ of these strains originating from the Cedar Grove site. Within this cluster, there were 21 subgroups (defined as strains that are $>90 \%$ similar within a cluster) with 2-6 strains each that grouped at $100 \%$ similarity level. Further, 16 of these subgroups contained only strains from the HV- field from Cedar Grove, indicating high similarity level among Cedar Grove isolates in the field where hairy vetch was never planted. In addition, over $60 \%$ of the strains with $100 \%$ similarity were isolated from different HV genotypes, which suggests high redundancy among the most ubiquitous strains captured in this collection of isolates. Except for a few cases with the USA-MD genotypes, it was only when inoculated with soils from different sites and different field histories that genotypes were nodulated by unique Rlv strains. The greatest number of clusters was identified at Ivanhoe, with 20 clusters, followed by Cedar Grove with 18, and Graham with 16 (Figs. 2-4). A few strains from each site did not fit into any identified cluster, including 9 from Graham, 4 from Cedar Grove and another 9 from Ivanhoe. Separate cluster analyses performed by site showed two out of three fields with HV history to have higher diversity than fields without history (Figs. 2-4). Cedar Grove in particular contained a very large cluster of 91 isolates of the total 173 , of which $85 \%$ came from the field with no HV history, suggesting rhizobia similarity in fields where no HV has been planted and increased diversity in fields with a history of hairy vetch planting. Within this large cluster, 33 subgroups were identified that clustered at $100 \%$ similarity, and 24 subgroups clustering at $>92 \%$ similarity level, again indicating a high level of similarity and low genetic diversity among resident rhizobial strains isolated from the field with no history of vetch cultivation. Graham contained one large cluster comprised of 51 of the total 161 strains at that site, of which a majority (65\%) were from the field with no HV history. This mixing of strains from both field types within a cluster demonstrates genetic similarity of rhizobia found in both fields at this site.

In Ivanhoe, only $12 \%$ of the isolates in the largest cluster (40 of 139 strains) were from HV - field, and the majority of strains were 
from fields with a cultivation history of vetch. Thus, contrary to Graham and Cedar Grove, data suggest that Ivanhoe soils contained a higher diversity in the HV- field than in the HV history field. Moreover, 8 of the 9 strains not belonging to any cluster were from HV- history field, further supporting our finding of greater diversity in the no history field as compared to the field with HV history at this site.

Redundancy analysis of the BOX-PCR patterns, when controlled for by site and HV history, reveals evidence of a HV host genotype influence on the populations of rhizobia that infect hairy

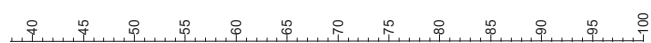

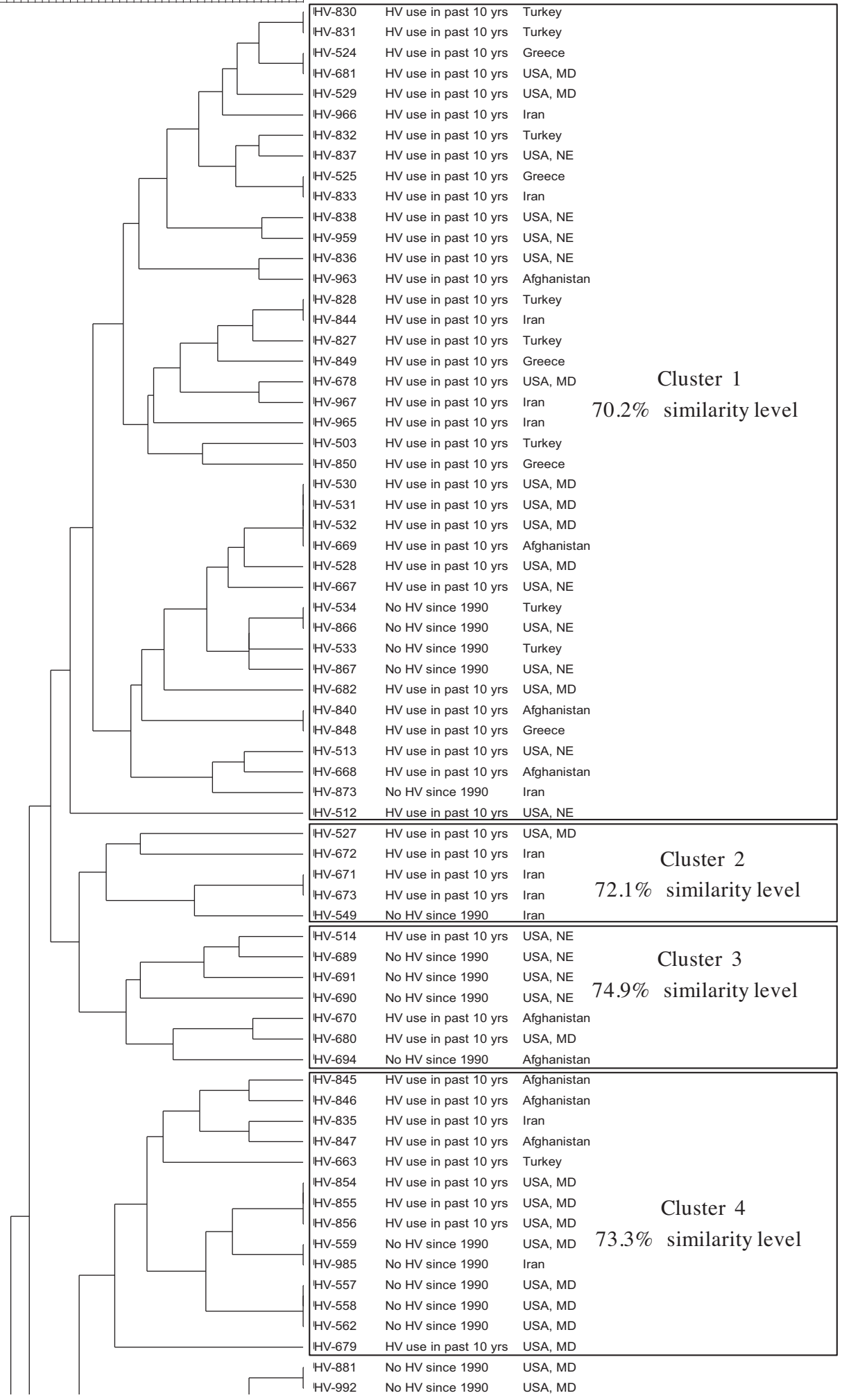

Fig. 2. Dendrogram of rhizobia strains isolated from ten hairy vetch genotypes inoculated with Ivanhoe soil from fields with and without a history of hairy vetch cultivation. 


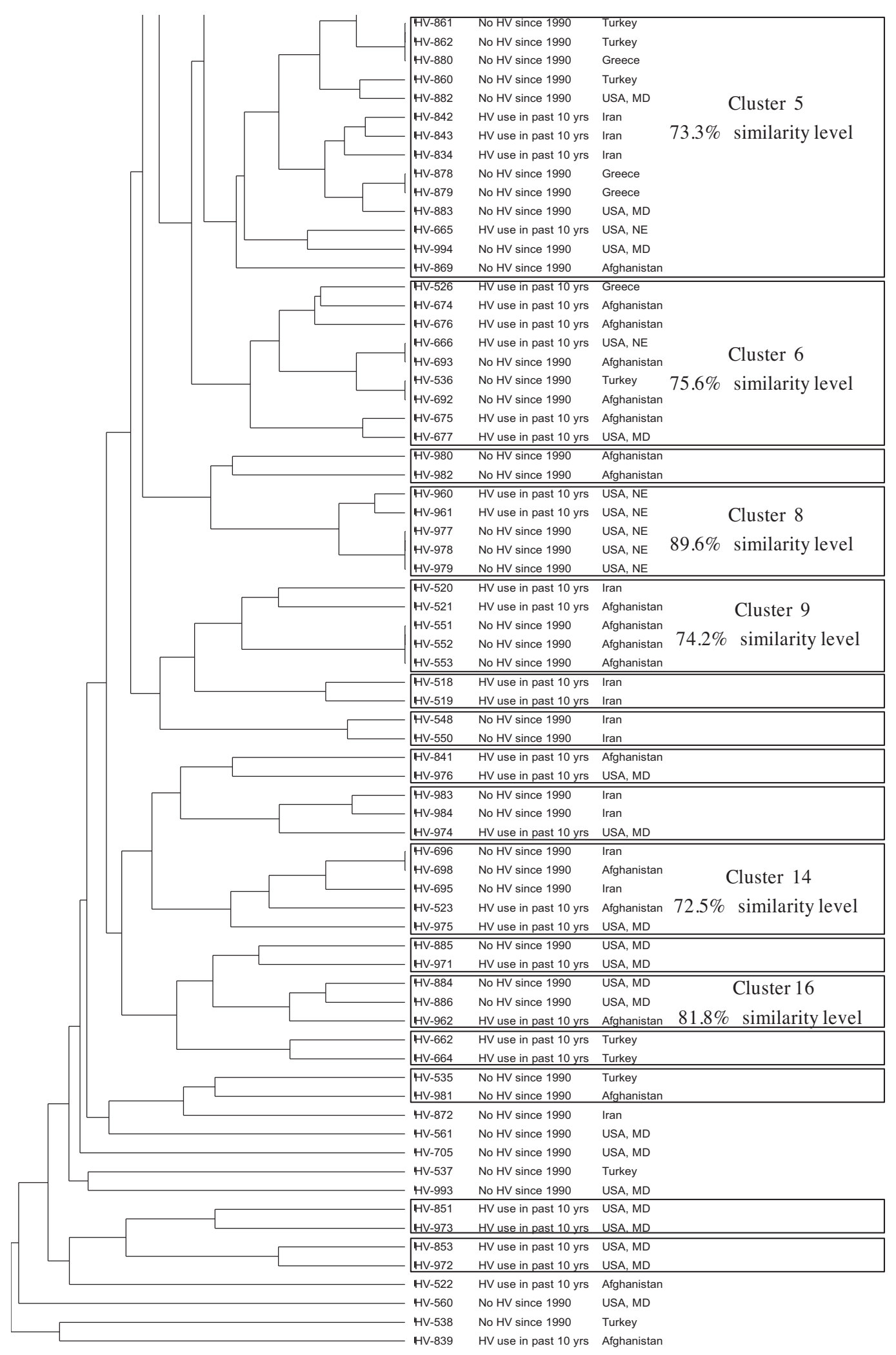

Fig. 2. (Continued).

vetch across the diverse sites studied in this report. Hairy vetch genotype explains $12.7 \%$ of the variation observed among all the isolates occupying nodules in this study. A bi-plot depicting the relative similarity among the rhizobia populations among the nodules of vetch genotypes is shown in Fig. 5. We used a vector approach to determine a correlation value for each HV genotype host and the BOX-PCR clusters of rhizobial isolate genomic fingerprint data (Fig. 5). The relationship among vetch genotype and rhizobial population fingerprint is clear when we compare the correlation coefficients in the context of HV genomic similarity. Three 
out of five pre-selected genetically similar HV genotype pairs cluster together (Fig. 5). Purple Bounty and Purple Prosperity rhizobial populations were found to be highly similar $(r=0.99)$, which is to be expected considering these two genotypes are sub-selections from a breeding project carried out at a single institution (USDA-ARS
Beltsville). Iran 2 and USA-NE $(r=0.86)$ and Afghanistan and Iran 1 $(r=0.98)$ also contained rhizobia that fell within genetically similar clusters. In contrast Turkey 1 and Turkey 2 have very low correlation $(r=0.85)$ despite similar origins and biochemical makeup (Maul et al., 2011).

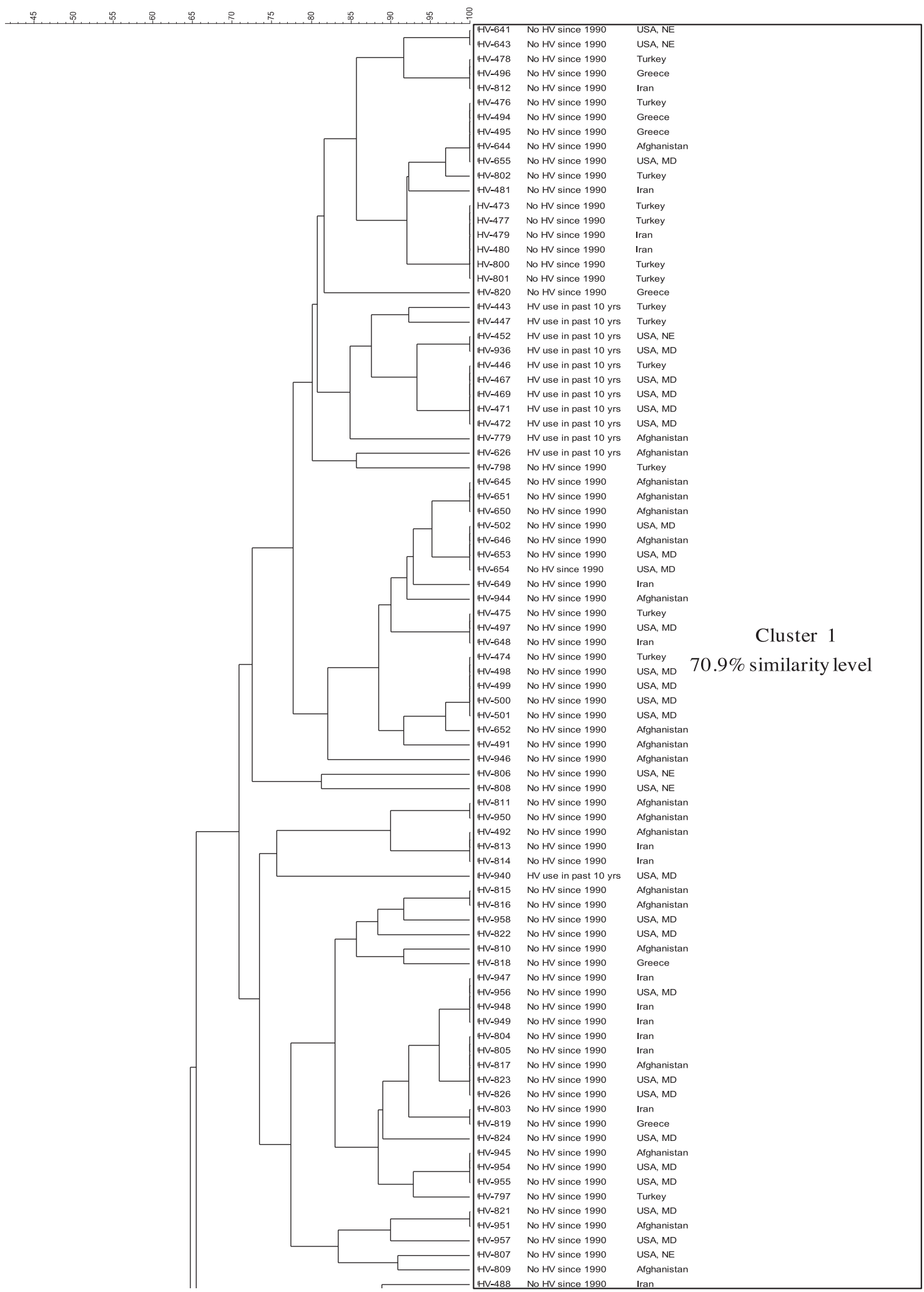

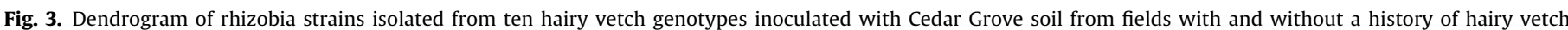
cultivation. 


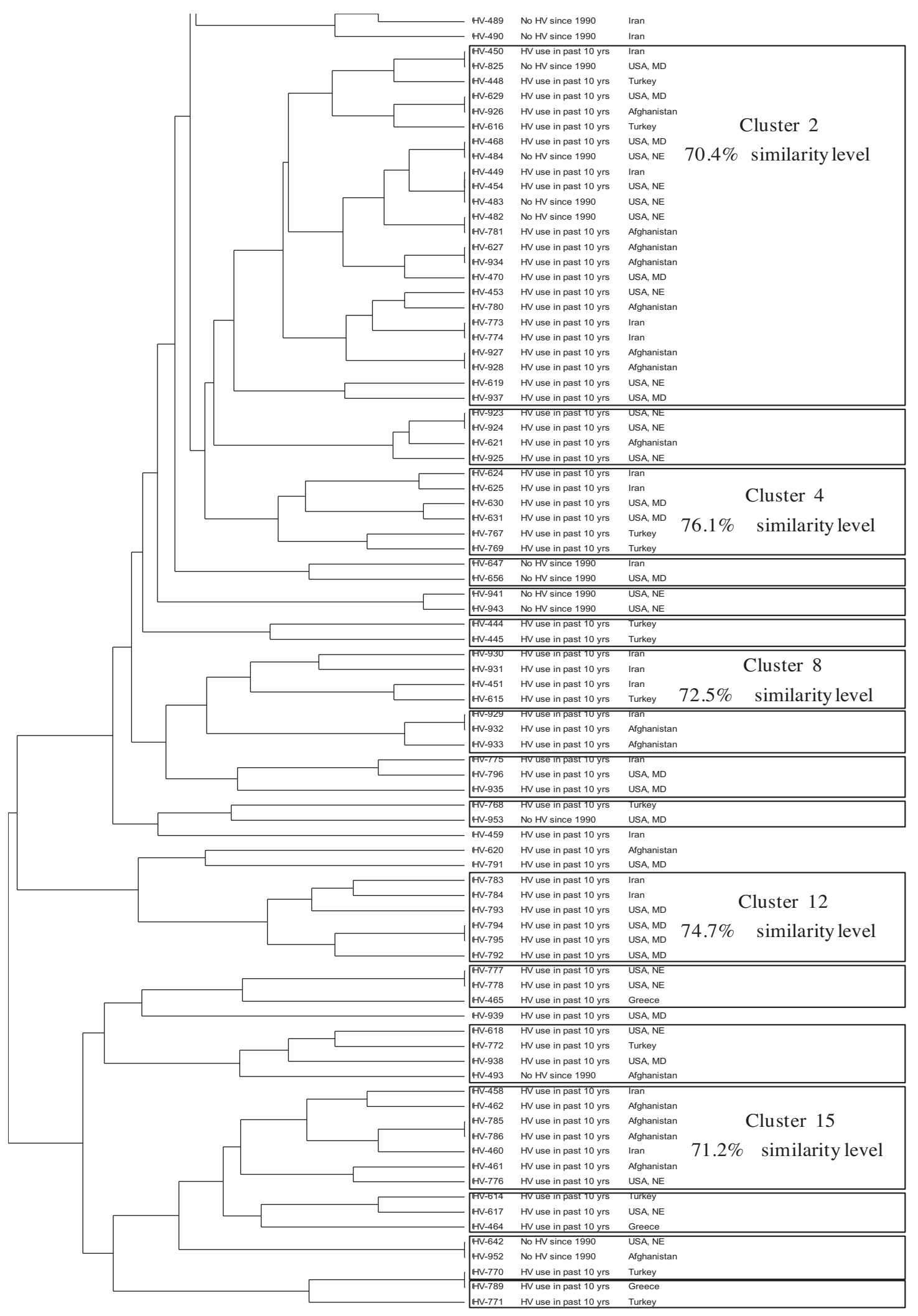

Fig. 3. (Continued).

\section{Discussion}

Our results showed high Rlv diversity between sites, demonstrated by others to often result from prevailing site-specific environmental variables imposing general genetic adaptations on soil rhizobia (Bernal and Graham, 2001; Mutch et al., 2003; Tian et al., 2007; Yang et al., 2008; Farooq and Vessey, 2009). Nominal values of soil phosphorus (P) and $\mathrm{pH}$ among the three sites varied considerably (Table 1 ). The importance of soil P on legumerhizobia symbiosis is well understood (Zaman-Allah et al., 2007; 
Wielbo and Skorupska, 2008; Leite Silva et al., 2010) and soil $P$ status has been shown to affect diversity of Rlv in the field (Labidi et al., 2003). As well, there is a large body of literature on the effect of soil pH, particularly highly acidic conditions, on the diversity of rhizobial populations (Aarons and Graham, 1991; Bala et al., 2001; Andrade et al., 2002a). Changing soil pH through liming can modify existing rhizobial populations (Andrade et al., 2002a), and highly acid conditions have been found to select for strains that are tolerant to high acid conditions (Bala et al., 2001). Consequently, as strains become more suited to a given environment, they also become distinct from strains in other environments resulting in increased diversity between sites. In our study, the Cedar Grove field with HV history was cultivated and consequently was limed periodically in preparation for planting.

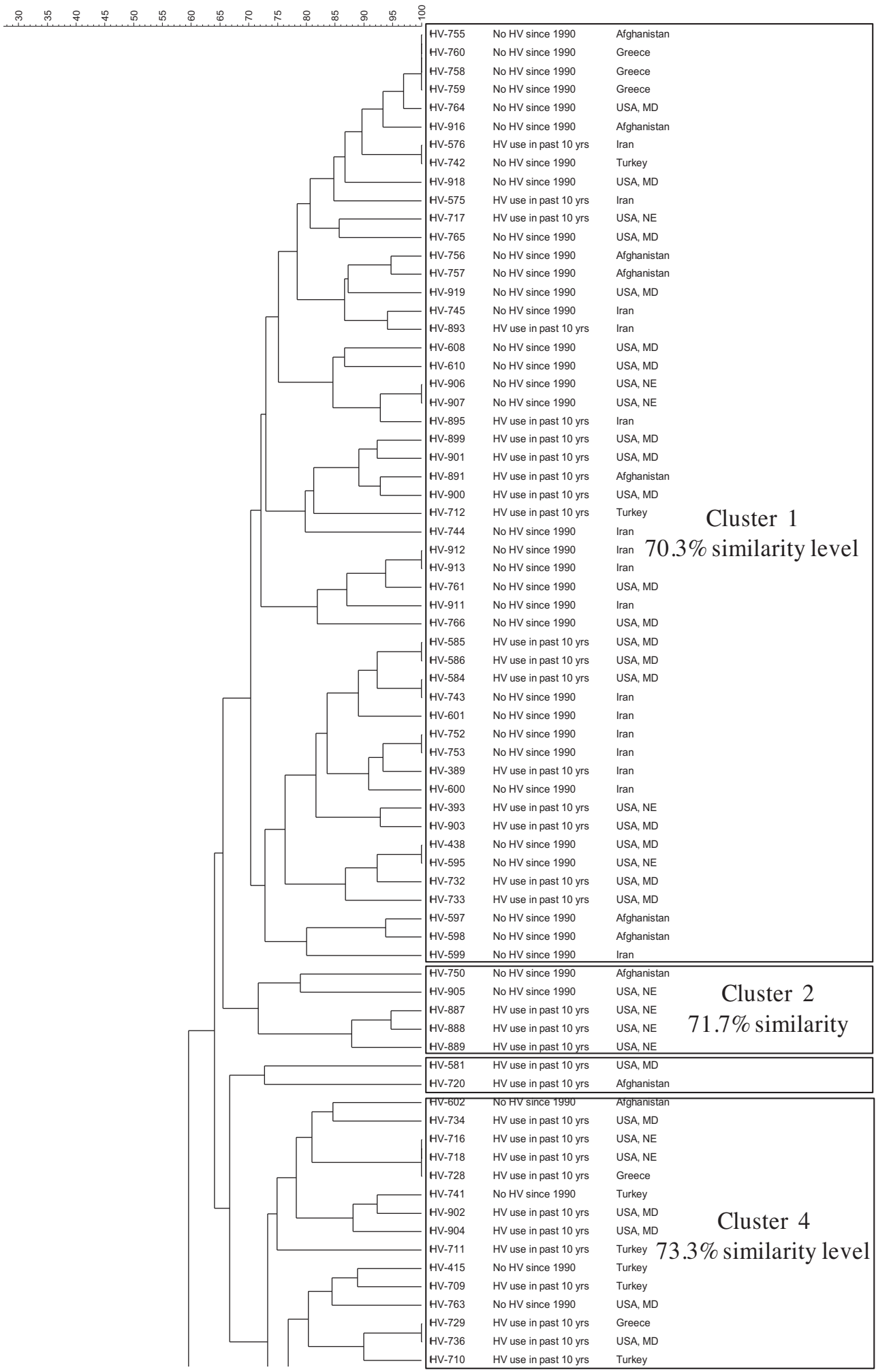

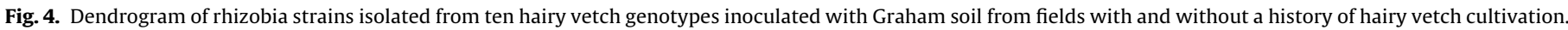




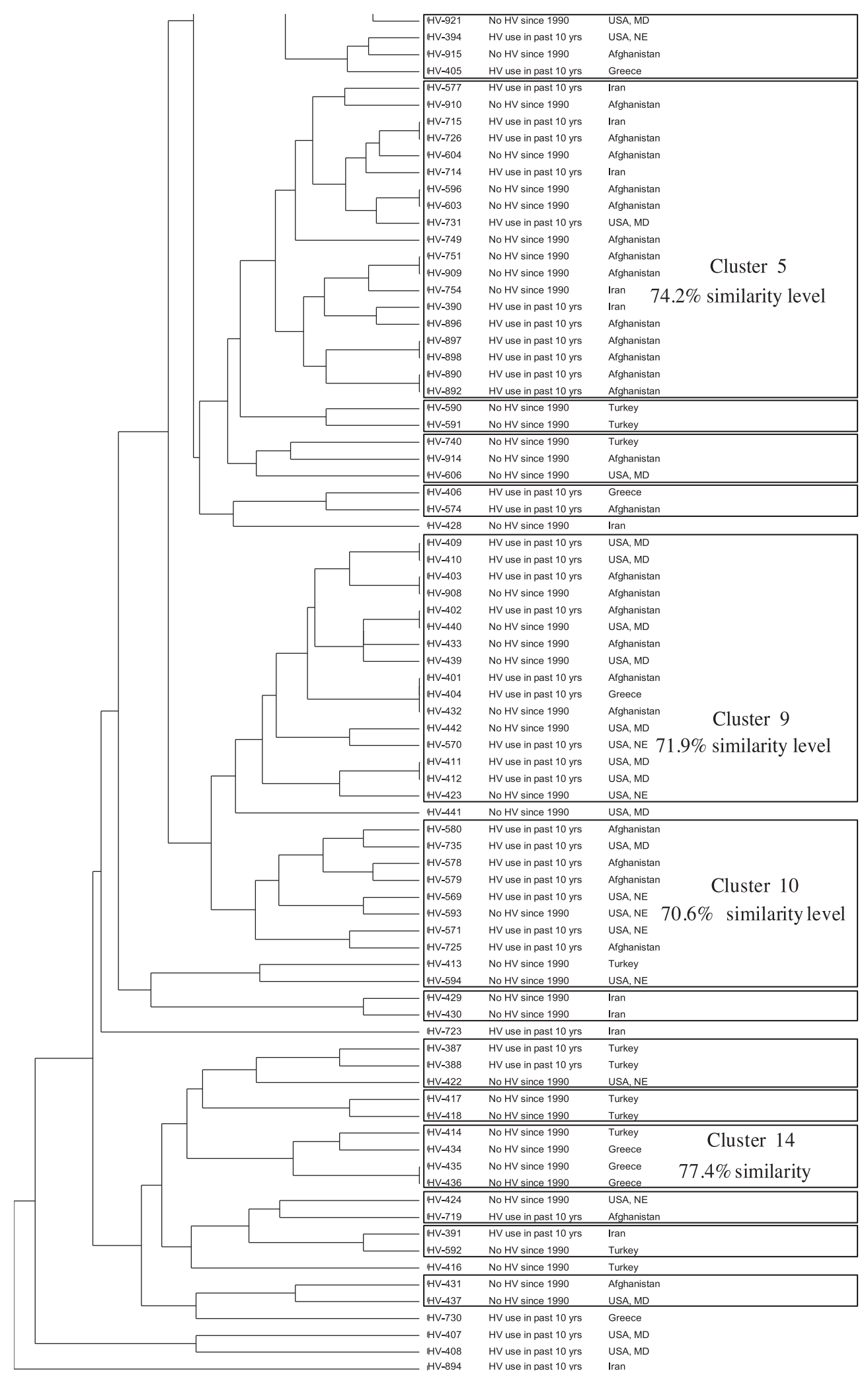

Fig. 4. (Continued).

This farm had the largest $\mathrm{pH}$ difference between the two fields, at 6.6 and 5.7 for the HV+ and HV- fields, respectively. The resulting change in $\mathrm{pH}$ may have created a more hospitable environment for Rlv and thus contributed to the increased diversity of Rlv strains identified in the HV+ fields relative to the HV- fields. Our research, in combination with previous findings, suggests that soil characteristics present in a site may influence population structure of resident Rlv between sites sampled in this study and may have broader implications when we conduct landscape level land management differences such as cover crop based rotations (which often incorporate different species and cultivars of legumes), or small grain bi-culture, which often dominates much of the current 


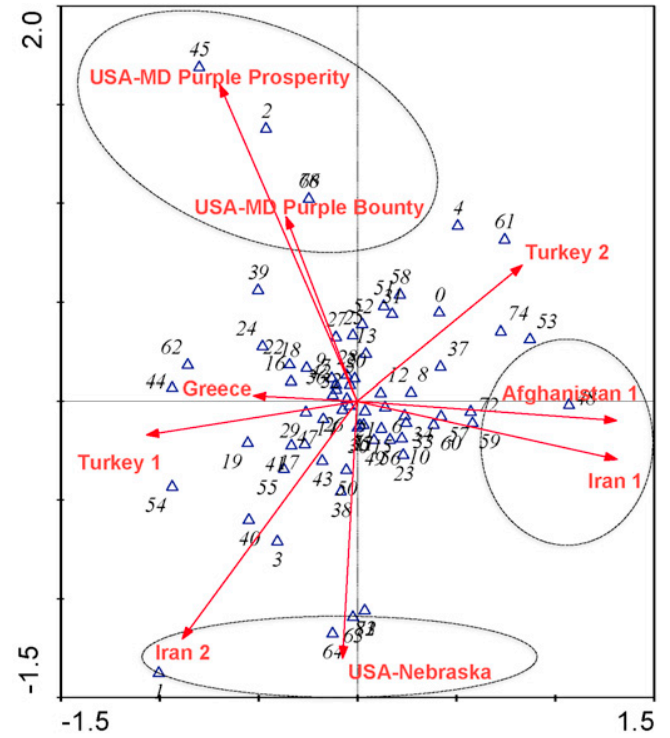

Fig. 5. Redundancy analysis of BOX-PCR fingerprint patterns from rhizobia isolated from nodules of five pairs of genetically related hairy vetch (Vicia villosia), site of collection (soil type) and HV history at the site were considered co-variates in the analysis. Dotted ovals indicate genetically related HV genotypes.

U.S. landscape and may incorporate one legume species (soybean).

Previous inoculation could also have been a driver of observed diversity in the HV fields. With the exception of the Ivanhoe site, there was greater rhizobial diversity in fields with histories of HV cultivation than in fields without history. Field inoculation with compatible rhizobia is known to increase the genetic diversity of resident rhizobia (de Fatima et al., 2007) likely by introducing new rhizobial strains into the environment with the potential for transfer of genetic material between strains. Several studies have suggested horizontal gene transfer to be a major factor contributing to rhizobial diversity (Aoki et al., 2010; Barcellos et al., 2007). The higher diversity observed in our field with HV history that had received past rhizobial inoculation (Cedar Grove) relative to the paired fields with no vetch history, may possibly be attributed to introduction of Rlv through inoculation. However, both Graham fields had never been inoculated, yet the cultivated field showed evidence of increased rhizobial diversity compared to the uncultivated field. This suggests that it is the presence of hairy vetch roots, or perhaps strains introduced to the field inadvertently on the legume seed at planting, that serve to increase diversity in this field rather than inoculation alone. Horizontal gene transfer may also potentially occur between existing strains in fields with no HV history (Zhang et al., 2001), and thus the mechanism through which legume cultivation increases diversity requires further attention.

Although studies have shown past cultivation of legume species to increase the population size of compatible rhizobia (Andrade et al., 2003; Chemining'wa and Vessey, 2006), ours is the first identified report documenting the explicit effect of legume cultivation history on genetic structure of compatible rhizobia. The high diversity in the Ivanhoe field that had never been planted to hairy vetch was unexpected, particularly since this field had the lowest $\mathrm{pH}$, often linked to reduced diversity as compared to similar fields with higher $\mathrm{pH}$ values. What made the Ivanhoe field with no HV history different from the other two HV - fields was that it had never been cultivated, thus rhizobia in this field would have encountered no selection pressure induced by agricultural management practices. Some management practices such as tillage have been shown to reduce the diversity of resident populations of rhizobia relative to untilled fields (Ferreira et al., 2000; de Fatima et al., 2007). Others have reported higher levels of diversity in uncultivated sites under native vegetation compared to cropped areas (Hungria et al., 2006). Additionally, we observed extremely low diversity of rhizobia in the Cedar Grove field with no history of hairy vetch, a field that had been tilled and intentionally planted to grass for over 20 years, with almost all Rlv isolates showing great similarity in their genetic makeup. The low pH of the Cedar Grove field could also result in selection of particular strain types adapted to acidic conditions, (Zahran, 1999; Hungria and Vargas, 2000; Andrade et al., 2002b). Our findings are consistent with Hungria et al. (2006), emphasizing that the rhizobial diversity in uncultivated soils may either be maintained or increased by agricultural practices such as no-till and crop rotations including a legume host, or reduced by practices such as tillage and monoculture.

Our results indicate that although $\mathrm{HV}$ genotype influences strain selection, it may be less important in determining diversity of associated rhizobia than site or a field having a history of vetch planting. In general, legume species in the tribe viciae are known to be specific in their symbiosis, and are particularly capable of selecting preferred rhizobial strains from diverse populations in the soil (Laguerre et al., 2003). Faba bean species ( . faba), another Rlv host, is known to be more discriminative than pea in strain selection, such that it is consistently nodulated by Rlv nod type $G$ (Laguerre et al., 2003). Pea genotype has also been suggested to influence diversity of Rlv isolates (Depret and Laguerre, 2008). Using REP-PCR techniques, Laguerre et al. (2003) showed that vetches are less discriminative of Rlv genomic backgrounds than pea or faba bean. Despite HV genotype being less of a discriminatory factor than site or HV history, we were able to identify a genotype effect on the diversity of rhizobia occupying genetically similar pairs of HV hosts. By controlling for site and HV history we were able to determine that vetch genotype accounted for almost $13 \%$ of the structure of the rhizobial population occupying nodules from distinct HV genotype host pairs. This suggests that underlying selection pressure for rhizobia at the plant host level appears to be at the sub-species level among HV genotypes. The results from the redundancy analysis and subsequent bi-plot correspond well to the banding pattern differences observed in Figure 1a and b; for example the patterns of USA-MD Purple Bounty and Purple Prosperity look similar whereas USA-NE is clearly different. Further studies with these isolates could use these distinct differences among rhizobial banding patterns as indicators of sub-groups within the rhizobia that associate with particular HV genotypes.

\section{Conclusions}

In this study we evaluated genetic structure of rhizobia isolated from fields with and without history of HV cultivation. Ten HV genotypes were used as trap hosts for resident Rlv across paired fields from three farms. Greater Rlv diversity was observed between sites than between fields with and without vetch history, thus showing site environment to be the main driver of strain diversity. Past history of hairy vetch cultivation increased diversity of Rlv within sites. We conclude that management approach, specifically planting of legume hosts and likely the application of rhizobia via inoculation, in combination with site specific factors can have a significant impact on rhizobial strains persisting in the field over time. Overall, understanding how previous cultivation of hairy vetch influences Rlv genetic diversity has important and far-reaching economic and ecological implications for farmers interested in using hairy vetch as a winter annual cover crop, as strain genetic structure can ultimately affect the amount of $\mathrm{N}_{2}$ fixed by cover crops used across agroecosystems. 


\section{Acknowledgements}

Farmers, Alex Hitt, Ken Dawson, Michael Fortune, Michael Porterfield and Stephan Hartman, are appreciated for making their fields available and willingly sharing their farm management information to help with the project. Funding support from a Fulbright Scholarship and the USDA-SARE program is greatly appreciated.

\section{References}

Aarons, S.R., Graham, P.H., 1991. Response of Rhizobium leguminosarum bv. phaseoli to acidity. Plant Soil 134, 145-151.

Andrade, D.D., Colozzi, A., Balota, E.L., Hungria, M., 2003. Long-term effects of agricultural practices on microbial community. In: Conservation Agriculture: Environment, Farmers Experiences, Innovations, Socio-economy, Policy, pp. 301-306.

Andrade, D.S., Murphy, P.J., Giller, K.E., 2002a. The diversity of phaseolus-nodulating rhizobial populations is altered by liming of acid soils planted with Phaseolus vulgaris L. in Brazil. Appl. Environ. Microbiol. 68, 4025-4034.

Andrade, D.S., Murphy, P.J., Giller, K.E., 2002b. Effects of liming and legume/cereal cropping on populations of indigenous rhizobia in an acid Brazilian oxisol. Soil Biol. Biochem. 34, 477-485.

Aoki, S., Kondo, T., Prevost, D., Nakata, S., Kajita, T., Ito, M., 2010. Genotypic and phenotypic diversity of rhizobia isolated from Lathyrus japonicus indigenous to Japan. Syst. Appl. Microbiol. 33, 383-397.

Bala, A., Murphy, P., Giller, K.E., 2001. Genetic diversity of rhizobia from natural populations varies with the soil dilution sampled. Soil Biol. Biochem. 33, 841-843.

Ballard, R., Charman, A., 2000. Nodulation and growth of pasture legumes with naturalised soil rhizobia - 1. Annual Medicago spp. Aust. J. Exp. Agric. 40, 939-948.

Barcellos, F.G., Menna, P., da Silva Batista, J.S., Hungria, M., 2007. Evidence of horizontal transfer of symbiotic genes from a Bradyrhizobium japonicum inoculant strain to indigenous diazotrophs Sinorhizobium (Ensifer) fredii and Bradyrhizobium elkanii in a Brazilian Savannah soil. Appl. Environ. Microbiol. 73, 2635-2643.

Bernal, G., Graham, P.H., 2001. Diversity in the rhizobia associated with Phaseolus vulgaris L. in Ecuador, and comparisons with Mexican bean rhizobia. Can. J. Microbiol. 47, 526-534.

Chemining'wa, G., Vessey, J., 2006. The abundance and efficacy of Rhizobium leguminosarum bv. viciae in cultivated soils of the eastern Canadian prairie. Soil Biol. Biochem. 38, 294-302.

de Fatima, L.M., Kaschuk, G., Alberton, O., Hungria, M., 2007. Soybean [Glycine max (L.) Merrill] rhizobial diversity in Brazilian oxisols under various soil, cropping, and inoculation managements. Biol. Fert. Soils 43, 665-674.

Depret, G., Houot, S., Allard, M.R., Breuil, M.C., Nouaim, R., Laguerre, G., 2004. Longterm effects of crop management on Rhizobium leguminosarum biovar viciae populations. FEMS Microbiol. Ecol. 51, 87-97.

Depret, G., Laguerre, G., 2008. Plant phenology and genetic variability in root and nodule development strongly influence genetic structuring of Rhizobium leguminosarum biovar viciae populations nodulating pea. New Phytol. 179, 224-235.

Farooq, F.T., Vessey, J.K., 2009. Genetic diversity of Bradyrhizobium japonicum within soybean growing regions of the north-eastern Great Plains of North America as determined by REP-PCR and ERIC-PCR profiling. Symbiosis 48, 131-142.

Ferreira, M.C., Andrade, D.D., Chueire, L.M.D., Takemura, S.M., Hungria, M., 2000. Tillage method and crop rotation effects on the population sizes and diversity of bradyrhizobia nodulating soybean. Soil Biol. Biochem. 32, 627-637.

Frey, S.D., Blum, L.K., 1994. Effect of pH on competition for nodule occupancy by type-i and type-ii strains of Rhizobium leguminosarum bv phaseoli. Plant Soil 163, 157-164.

Giongo, A., Passaglia, L.M.P., Freire, J.R.J., de Sa, E.L.S., 2007. Genetic diversity and symbiotic efficiency of population of rhizobia of Phaseolus vulgaris L. in Brazil. Biol. Fert. Soils 43, 593-598.

Graham, P.H., Draeger, K.J., Ferrey, M.L., Conroy, M.J., Hammer, B.E., Martinez, E., Aarons, S.R., Quinto, C., 1994. Acid pH tolerance in strains of rhizobium and bradyrhizobium, and initial studies on the basis for acid tolerance of Rhizobium tropici Umr1899. Can. J. Microbiol. 40, 198-207.

Grange, L., Hungria, M., 2004. Genetic diversity of indigenous common bean (Phaseolus vulgaris) rhizobia in two Brazilian ecosystems. Soil Biol. Biochem. 36, 1389-1398.

Grossman, J.M., Schipanski, M.E., Sooksanguan, T., Seehaver, S., Drinkwater, L.E., 2011. Diversity of rhizobia in soybean [Glycine max (Vinton)] nodules varies under organic and conventional management. Appl. Soil Ecol. 50, 14-20.
Hungria, M., Vargas, M.A.T., 2000. Environmental factors affecting N-2 fixation in grain legumes in the tropics, with an emphasis on Brazil. Field Crops Res. 65, 151-164.

Hungria, M., Chueire, L.M.O., Megias, M., Lamrabet, Y., Probanza, A., GuttierrezManero, F.J., Campo, R.J., 2006. Genetic diversity of indigenous tropical fast-growing rhizobia isolated from soybean nodules. Plant Soil 288, 343-356.

Hynes, M.F., Oconnell, M.P., 1990. Host plant effect on competition among strains of Rhizobium-leguminosarum. Can. J. Microbiol. 36, 864-869.

Kaschuk, G., Hungria, M., Andrade, D.S., Campo, R.J., 2006. Genetic diversity of rhizobia associated with common bean (Phaseolus vulgaris L.) grown under no-tillage and conventional systems in Southern Brazil. Appl. Soil Ecol. 32, 210-220.

Labidi, M., Dahmane, A.B.K., Ben Mansour, H., Khiari, L., Ahmad, D., 2003. Soil Pstatus and cultivar maturity effects on pea-rhizobium symbiosis. Plant Soil 252. 339-348.

Laguerre, G., Louvrier, P., Allard, M.R., Amarger, N., 2003. Compatibility of rhizobial genotypes within natural populations of Rhizobium leguminosarum biovar viciae for nodulation of host legumes. Appl. Environ. Microbiol. 69, 2276-2283.

Laguerre, G., Depret, G., Bourion, V., Duc, G., 2007. Rhizobium leguminosarum bv. viciae genotypes interact with pea plants in developmental responses of nodules, roots and shoots. New Phytol. 176, 680-690.

Lapinskas, E.B., 2007. The effect of acidity on the distribution and symbiotic efficiency of rhizobia in Lithuanian soils. Eurasian Soil Sci. 40, 419-425.

Leite Silva, E.F., Ferreira de Araujo, A.S., dos Santos, V.B., Pinheiro Leal Nunes, L.A., Vieira Carneiro, R.F., 2010. Biological N-2 fixation in cowpea under different rates and sources of soluble phosphorus. Biosci. J. 26, 394-402.

Lima, A.S., Abrahao Nobrega, R.S., Barberi, A., da Silva, K., Ferreira, D.F., de Souza Moreira, F.M., 2009. Nitrogen-fixing bacteria communities occurring in soils under different uses in the Western Amazon Region as indicated by nodulation of siratro (Macroptilium atropurpureum). Plant Soil 319, 127-145.

Maul, J., Mirsky, S., Emche, S., Devine, T., 2011. Evaluating a germplasm collection of the cover crop hairy vetch for use in sustainable farming systems. Crop Sci. 51, 2615-2625

Mothapo, N.V., 2011. Nodulation and Rhizobia Diversity Associated with Distinct Hairy Vetch Genotypes. North Carolina State University Libraries, North Carolina State University.

Mutch, L.A., Tamimi, S.M., Young, J.P.W., 2003. Genotypic characterization of rhizobia nodulating Vicia faba from the soils of Jordan: a comparison with UK isolates. Soil Biol. Biochem. 35, 709-714.

Mutch, L.A., Young, J.P.W., 2004. Diversity and specificity of Rhizobium leguminosarum biovar viciae on wild and cultivated legumes. Mol. Ecol. 13, 2435-2444.

Palmer, K.M., Young, J.P.W., 2000. Higher diversity of Rhizobium leguminosarum biovar viciae populations in arable soils than in grass soils. Appl. Environ. Microbiol. $66,2445-2450$.

Power, J.F., Doran, J.W., Koerner, P.T., 1991. Hairy vetch as a winter cover crop for dryland corn production. J. Prod. Agric. 4, 62-67.

Sainju, U.M., Rahman, S., Singh, B.P., 2001. Evaluating hairy vetch residue as nitrogen fertilizer for tomato in soilless medium. HortScience 36, 90-93.

Sarita, S., Sharma, P.K., Priefer, U.B., Prell, J., 2005. Direct amplification of rhizobial nodC sequences from soil total DNA and comparison to nodC diversity of root nodule isolates. FEMS Microbiol. Ecol. 54, 1-11.

Tian, C.F., Wang, E.T., Han, T.X., Sui, X.H., Chen, W.X., 2007. Genetic diversity of rhizobia associated with Vicia faba in three ecological regions of China. Arch. Microbiol. 188, 273-282.

Vessey, J., Chemining'wa, G., 2006. The genetic diversity of Rhizobium leguminosarum bv. viciae in cultivated soils of the eastern Canadian prairie. Soil Biol. Biochem. $38,153-163$.

Vincent, J.M., 1970. A Manual for the Practical Study of Root-nodule Bacteria. International Biological Programme. Blackwell Scientific, Oxford.

Wielbo, J., Skorupska, A., 2008. Influence of phosphate and ammonia on the growth, exopolysaccharide production and symbiosis of Rhizobium leguminosarum bv. trifolii TA1 with clover (Trifolium pratense). Acta Biol. Hung. 59, 115-127.

Yang, ChengYun, Yang, JiangKe, Li, YouGuo, Zhou, JunChu, 2008. Genetic diversity of root-nodulating bacteria isolated from pea (Pisum sativum) in subtropical regions of China. Sci. China Ser. C Life Sci. 51, 854-862.

Zahran, H.H., 1999. Rhizobium-legume symbiosis and nitrogen fixation under severe conditions and in an arid climate. Microbiol. Mol. Biol. Rev. 63, 968-989.

Zaman-Allah, M., Sifi, B., L'Taief, B., El Aouni, M.H., Drevon, J.J., 2007. Symbiotic response to low phosphorus supply in two common bean (Phaseolus vulgaris L) genotypes. Symbiosis 44, 109-113.

Zhang, X.X., Kosier, B., Priefer, U.B., 2001. Genetic diversity of indigenous Rhizobium leguminosarum bv. viciae isolates nodulating two different host plants during soil restoration with alfalfa. Mol. Ecol. 10, 2297-2305. 